\title{
Soil hydraulic properties: influence of tillage and cover crops
}

\begin{abstract}
Understanding the effects of cover crops and tillage on soil physical properties is important for determining soil productivity. This study was conducted at Lincoln University's Freeman Center, USA to evaluate the effects of tillage and cover crop management on soil hydraulic properties. The field site included three replicate blocks in a randomized complete block design with each plot measuring $21.3 \mathrm{~m}$ in length and $12.2 \mathrm{~m}$ in width. Treatment factors were tillage at two levels (moldboard plow tillage vs. no tillage) and cover crop at two levels (cereal rye (Secale cereal) cover crop vs. no cover crop). Soil samples were collected in late spring/early summer from each treatment at $10-\mathrm{cm}$ depth increments from the soil surface to a depth of 40 $\mathrm{cm}$ using cores (76.2-mm diameter and 76.2-mm length). Soil bulk density was $13 \%$ lower with tillage compared with no-tillage. Volumetric water content was significantly higher at 0.0 and $-0.4 \mathrm{kPa}$ pressures with tillage compared with no tillage. Tillage increased the proportion of coarse mesopores by $32 \%$ compared with no tillage, resulting in $87 \%$ higher saturated hydraulic conductivity (Ksat). Cover crop increased the proportion of macropores by $24 \%$ compared with no cover crop; this can potentially increase water infiltration and reduce runoff. As a result of higher macroporosity, Ksat was higher under cover crop compared with no cover crop. This study demonstrated that tillage can benefit soil hydraulic properties in the short term, but these effects may not persist over time. Cover crops may slightly improve soil hydraulic properties, but longer term studies are needed to evaluate the long-term effects.
\end{abstract}

Keyword: Pore size distribution; Saturated hydraulic conductivity; Soil bulk density; Soil water retention; Volumetric water content 